Cahiers $d u$ MONDE RUSSE

\section{Cahiers du monde russe}

Russie - Empire russe - Union soviétique et États indépendants

$52 / 1 \mid 2011$

Varia

\title{
Šuvalov À Rome (1765-1774)
}

Histoire d'une dédicace

\section{Olga Medvedkova}

\section{(2) OpenEdition}

1 Journals

Édition électronique

URL : https://journals.openedition.org/monderusse/9321

DOI : $10.4000 /$ monderusse. 9321

ISSN : $1777-5388$

Éditeur

Éditions de l'EHESS

\section{Édition imprimée}

Date de publication : 5 mars 2011

Pagination : 45-73

ISBN : 978-2-7132-2351-8

ISSN : $1252-6576$

\section{Référence électronique}

Olga Medvedkova, «S Suvalov À Rome (1765-1774) », Cahiers du monde russe [En ligne], 52/1 | 2011, mis en ligne le 28 mars 2014, consulté le 04 septembre 2022. URL : http://journals.openedition.org/ monderusse/9321 ; DOI : https://doi.org/10.4000/monderusse.9321

Ce document a été généré automatiquement le 4 septembre 2022

Tous droits réservés 


\title{
Šuvalov À Rome (1765-1774)
}

\author{
Histoire d'une dédicace
}

\section{Olga Medvedkova}

1 Le frontispice du deuxième volume des Vasi, candelabri, cippi, sarcofagi, tripodi, lucerne e ornamenti antichi... (1778) ${ }^{2}$ de Giovanni Battista Piranesi (1720-1778) est dédicacé à Ivan Ivanovič Šuvalov (1727-1797), l'un des personnages les plus haut en couleur du XVIII ${ }^{\mathrm{e}}$ siècle russe. Ce frontispice gravé par l'artiste (ill. 1) représente le « bas-relief antique qui se voit sous le portique de l'église des Saints-Apôtres ", sur lequel on voit un aigle aux ailes déployées entouré d'une couronne de laurier, ainsi que les vases « tirés du recueil du Chevalier Ghezzi conservé à la bibliothèque vaticane ». L'un de ces vases est dédicacé à l'«Eccellentiss. Viro Theodorico Principe Gallitzin», le prince Fedor Golicyn, jeune neveu de Šuvalov que celui-ci accompagnait au cours de son Grand Tour. Ivan Šuvalov lui-même est doté dans ce frontispice du titre de " Promotor delle belle arti ». En italien comme en français, "promotore » se dit d'une personne qui conçoit l'idée, qui donne la première impulsion, qui provoque la création. 
III.1 - Giovanni Battista Piranesi, Vasi, Candelabri, Cippi, Sarcofagi, Tripodi, Lucerne, Ed Ornamenti Antichi..., Roma, v. 1778, tome second, frontispice «A Sua Eccellenza il Sigg. General

Schouvaloff... ». BINHA

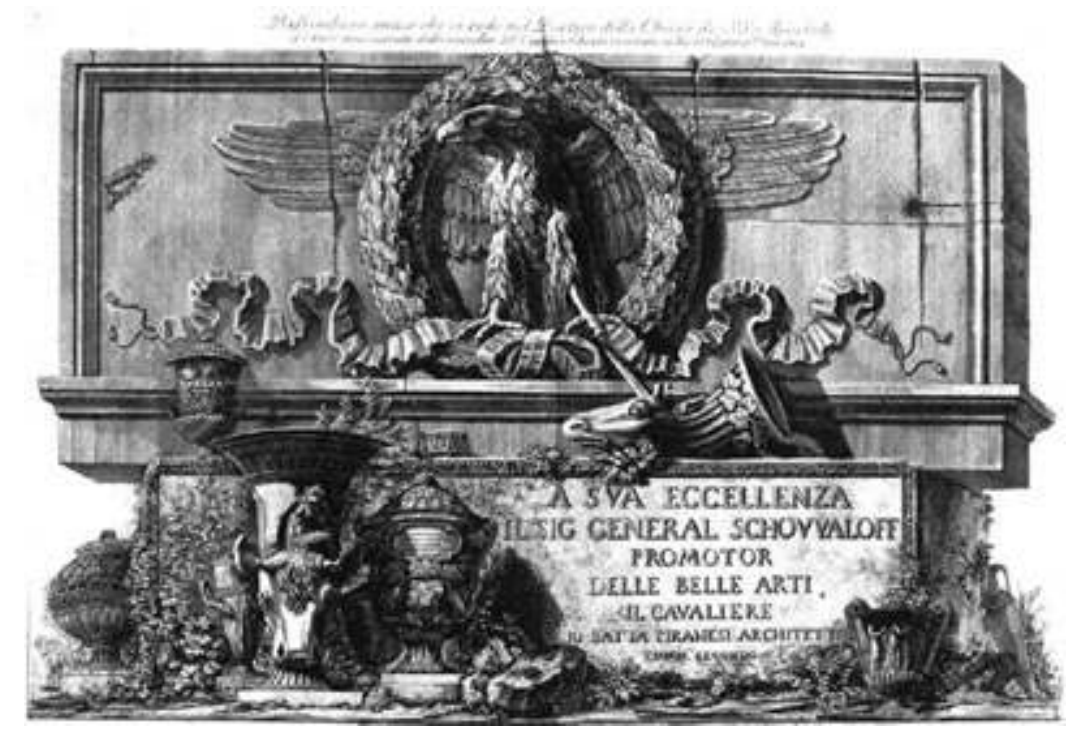

Le recueil des Vasi représente un ensemble de planches d'« antiquités », vraies et fausses, dont chacune porte une ou plusieurs dédicaces aux clients de Piranesi, des nobles européens, essentiellement aux milordi britanniques réalisant leur Grand Tour. Or, aucun d'eux n'y est doté du titre de "promotore». Le plus souvent ils sont qualifiés d'« amatore », ou bien de " saggio e dotto stimatore delle romane antiquità [connaisseur savant et avisé des antiquités romaines] », ou d'autres fois encore de " seguace delle belle arti [zélateur des beaux-arts] »3.

Quelles furent donc les activités de Šuvalov durant son séjour romain, qui lui valurent cette dédicace et ce titre? Ceux-ci avaient-ils une signification particulière? Quel rôle le Russe joua-t-il dans les cercles cosmopolites réunis à Rome dans les années 1760-1770 ?

Quelques nouvelles sources, que nous avons identifiées, nous ont permis d'esquisser une réponse à ces questions. Il s'agit, notamment, de la correspondance inédite de Šuvalov avec lord William Hamilton à qui, par ailleurs, Piranesi avait dédicacé la première planche du premier volume des Vasi représentant le célèbre vase de Warwick ${ }^{4}$.

\section{En Russie 5}

5 Né aux environs de Moscou dans une famille de petite noblesse qui avait d'importants appuis à la cour, Šuvalov " perdit son père de bonne heure et ne reçut jusqu'à l'âge de dix ans que l'éducation fort limitée que son argent pouvait lui procurer à la campagne. Plus tard il étudia avec Souvaroff chez un savant professeur de Moscou, fit de rapides progrès en mathématiques, apprit le français et l'allemand et, âgé à peine de 14 ans, lorsqu'Elisabeth monta sur le trône, fut attaché en qualité de page à la cour de cette princesse. $»^{6}$ Cette place à la cour fut obtenue par le jeune Šuvalov grâce à l'intervention de ses cousins qui, en l'introduisant dans l'entourage proche de l'impératrice, semblaient miser sur la beauté de leur jeune parent. En automne 1749, à Moscou, Elisabeth, âgée de quarante ans, remarqua le page de dix-huit ans son cadet. Šuvalov devint son favori, statut qu'il conserva jusqu'à la mort de l'impératrice en 1761. 
Or, rapidement, d'un petit-maitre, ce « Pompadour russe » (selon les mots de Voltaire) devint un Kulturträger de grande envergure. Dans les années 1750, il mena à bien la création de deux institutions centrales dans l'histoire de la culture russe - l'université de Moscou et l'Académie des beaux-arts de Saint-Pétersbourg. Il logea des artistes chez lui, s'adonna personnellement à la gravure ${ }^{7}$, réunit une bibliothèque et une collection de tableaux ${ }^{8}$. Dans toutes ces entreprises, il démontra une ouverture exceptionnelle à la culture européenne.

Deux sources d'inspiration pouvaient l'animer à cette époque.

8 La première provenait du modèle de la construction culturelle à l'européenne et, ex nihilo, ébauché par le père d'Elisabeth. À l'époque où l'Académie lui tenait à cœur, il interrogeait les anciens agents de Pierre le Grand sur leurs activités en Europe. Ainsi, en 1753, il s'adressait à l'agent de Pierre, Jurij Kologrivov, pour être instruit des modalités des envois des artistes russes en Italie ${ }^{9}$. Correspondant de Voltaire durant la préparation de l'Histoire de l'empire de Russie sous Pierre le Grand, Šuvalov avait dû lui-même consulter les documents et s'entretenir avec les historiens ${ }^{10}$.

9 La seconde inspiration lui venait de sa correspondance avec les Lumières de l'Europe qui n'hésitaient pas à conseiller le jeune parvenu. Dans sa lettre du 10 juin 1761, Helvetius pouvait écrire à Šuvalov :

10 Songez que le nom d'une infinité de peuples puissants s'est enseveli sous les ruines de leurs capitales; que partout, peut-être, le nom Russe, doit encore subsister lors même que le temps en aura détruit la puissance. Si les Grecs n'eussent vaincû que l'Asie, leur nom serait maintenant oublié! C'est aux monuments qu'ils ont élevés, aux sciences \& aux arts, qu'ils doivent encore le tribut d'admiration que notre reconnoissance leur paye mais pour former de grands hommes, il faut encourager la liberté de penser; il ne faut pas que le ciseau de la superstition, et de la théologie puisse couper les ailes du Genie. ${ }^{11}$

Dans son élan rhétorique, Helvetius comparait allégrement les Russes aux Grecs anciens sans pour autant se rendre compte des conclusions culturelles, idéologiques et politiques que les Russes étaient capables de tirer de ce genre de comparaison.

L'avènement de Catherine II entraîna le quasi-exil de Šuvalov. En avril 1763, il quitta la Russie et passa à l'étranger quelque quatorze années ${ }^{12}$. Il parcourut l'Europe et s'arrêta d'abord six mois à Vienne. Là, il s'interrogea sur l'itinéraire de son voyage ${ }^{13}$. Finalement Šuvalov choisit Paris mais il n'y resta que de janvier à novembre 1764.

\section{À Paris}

Le cercle de connaissances que se fit Šuvalov pendant son séjour parisien peut être rétabli grâce à sa correspondance ${ }^{14}$. Sa réputation déjà faite par Voltaire, il devint l'habitué des salons des grandes dames parisiennes: Mme Geoffrin, Mme du Deffand, Mme de Genlis et Mme Necker, et se lia d'amitié avec le prince de Ligne, Buffon (à qui il fournit une aide financière), Lamarck, Marmontel, Necker. La duchesse de Choiseul (" grand'maman »), fut l'une de ses relations les plus proches. Dans son salon, Šuvalov pouvait rencontrer l'abbé Barthélemy et le comte de Caylus. La société française le recevait chaleureusement et recherchait son amitié. Ainsi, Mme Geoffrin lui écrivait plus tard :

Vous avez été aimé, considéré et recherché à Paris, vous nous devez de la reconnoissance ; si nous eussions pu nous flatter de vous voir un des nos cytoyens, 
vous auriez été encore plus content de nous. Je parle d'après ce que j'ai senti. Je vous assure, mon cher Comte, que je me serois bien plus attachée à vous, que j'aurois eu bien plus de plaisir à vous voir, si j'avois pû espérer de vous voir fixé avec nous et de vous y voir heureux. Revenez, revenez à Paris, c'est le seul endroit qui puisse engourdir les regrets de tout ce que vous avez perdu. ${ }^{15}$

Votre absence, Mr Le comte, fait un grand vide dans notre société. La facilité avec laquelle vous avez sçû descendre du rang le plus élevé à la vie d'un particulier sans la moindre ostentation de simplicité ni de philosophie se joint à vos aimables qualités pour vous concilier tous les cœurs et vous faire regretter sans cesse.... ${ }^{16}$

15 La correspondance de Šuvalov avec ses amis parisiens était emplie de nouvelles politiques et littéraires ${ }^{17}$, mais quasiment jamais ne faisait état des beaux-arts. Paradoxalement, en pénétrant dans les milieux parisiens intensément mêlés aux arts, celui qui était si fortement préoccupé par les «affaires culturelles » en Russie, ne semblait pas s'en soucier. En choisissant le rôle d'un homme privé en exil - ce qui plaisait tant aux Parisiens - Šuvalov abandonna du même coup tout « commerce » artistique. Il semblerait que cette activité était liée pour lui à l'idée de la vie active ainsi qu'à l'ambition d'un homme d'État.

16 En 1765, Šuvalov quitta Paris pour passer quelques mois à Londres ${ }^{18}$. Il y fut entièrement séduit par les jardins ${ }^{19}$ et fit connaissance de plusieurs amateurs d'art britanniques, notamment de Charles Greville, le neveu de l'envoyé à Naples William Hamilton, ainsi que de Walpole. Tous les deux lui servirent, plus tard, aussi bien de commissionnaires que de modèles en matière de goût ${ }^{20}$. Ce fut durant ce voyage à Londres, auprès des amateurs britanniques, que Šuvalov semble avoir compris les avantages qu'offrait à cette époque-là le séjour en Italie.

17 Après un court intermède à Paris, il se rendit donc à Rome et y resta jusqu'en 1774, en dépit des appels chaleureux au retour que lui lançaient régulièrement les Parisiens ${ }^{21}$.

\section{Les débuts romains}

18 Ce n'est pas que ce séjour romain lui convenait ou lui était particulièrement agréable. Il le voyait plutôt comme un exil volontaire dans une province où, à la différence de Paris, l'ennui régnait en maître :

L'Italie nous ennuie tous deux [lui et son neveu, Fedor Golicyn, qui voyageait avec lui]; il n'y a rien hormis le climat et les arts. Sans les maisons des ministres étrangers, nous ne saurions que faire ici. Tous les ministres étrangers sont mes amis, et c'est pourquoi votre fils y séjourne souvent; leur commerce est incomparablement plus utile et agréable que celui qui a cours ici. ${ }^{22}$

19 Dans ses lettres à sa sœur, Šuvalov décrivait Rome, ville provinciale, habitée par une noblesse aux habitudes ridicules :

Comme je vous l'ai écrit précédemment, il n'y a pas de divertissements ici, à Rome, mais la vie y est fort paisible. Mon goût [ohota] pour les arts ainsi que mon commerce des ministres étrangers et de quelques seigneurs romains, voilà tout mon plaisir. [...] Ils [les nobles romains] diffèrent tant des autres nations éclairées [prosveščennyh] par leurs mœurs, leur commerce [obhoždeniem] et leur comportement qu'on croirait que ces gens viennent seulement de recevoir de bons établissements [blagoučreždenija]. Cela est étrange : ce pays dont sont sorties toutes les sciences, tous les arts demeure à présent dans une telle ignorance [nevežestvo], particulièrement cette ville : la capitale des vainqueurs et des maîtres du monde 
entier dans les temps antiques se trouve aujourd'hui dans cet état ! Ce qu'ils ont de particulièrement insupportable, c'est leur morgue et leurs cérémonies : pas une dame ne sortira de son carrosse avant qu'on ne lui portât des flambeaux. Et le plus drôle est leur souper qui ne vaut pas un rouble, mais dont les plats sont portés aux flambeaux. Il y a bien d'autres sots usages de cette espèce. Ils reconnaissent euxmêmes l'ennui où ils demeurent, mais ils ne savent pas trouver à s'amuser [vesel'ja najti ne umejut]. Et leurs cérémonies sont la cause de tout. ${ }^{23}$ Narbonne du Puy Montbrun ${ }^{28}$ ou le cardinal de Bernis, étaient très nombreux à Rome. Šuvalov eut d'ailleurs recours au cardinal plusieurs années encore après son retour en Russie, pour " entourer» les touristes russes ainsi que ses autres protégés ${ }^{29}$. Ce fut également parmi les Français romains qu'il embaucha le précepteur de son neveu. Son choix fut remarquable : il s'agissait d'un mathématicien minime, le père Jacquier, celui pour qui Clérisseau dessina la célèbre cellule ruine au Convento della Trinita dei Monti ${ }^{30}$. En été, le père Jacquier emmenait le jeune Fedor Golicyn à Albano pour le guérir de sa mélancolie qui, sans doute, était en grande partie conventionnelle ${ }^{31}$. Parmi les amitiés romano-germaniques de Šuvalov, on peut citer le savant précepteur et agent Conrad- 
René Koch. Ce fut Koch qui aida Šuvalov dans sa quête d'un sculpteur pour le buste de Catherine, qui devait avoir celui de Cicéron comme pendant.

Durant ses années italiennes, Šuvalov voyagea intensément. Il séjourna à plusieurs reprises à Florence, à Pise et à Naples. À Naples, particulièrement, ses attaches furent solides. Wenzel Anton von Kaunitz, chancelier, ministre des Affaires étrangères et agent artistique des Habsbourg ${ }^{32}$, lui écrivait de Naples en 1770 :

J'étois piqué du séjour que vous avez fait à Pise. J'aurois voulu que vous donnassiez la préférence aux bains d'Ischia et à l'air de Naples. Vous devez trouver partout des gens qui vous estiment, mais je vous garantie qu'il n'y en a pas qui s'intéressent à tout ce qui vous regarde aussi sincèrement que vos amis de Naples ou plutôt de Vienne... ${ }^{33}$

Les liens entre les élites à Naples, à Vienne et à Saint-Pétersbourg étaient à l'époque plus que solides. Ce fut l'ambassadeur de la Russie à Vienne, Dmitrij M. Golicyn, qui procura aux Russes les premières éditions sur les antiquités d'Herculanum. Sa correspondance témoigne de l'avidité avec laquelle l'impératrice et la cour de Saint-Pétersbourg se jetaient sur ces éditions, si difficiles à obtenir ${ }^{34}$.

28 Mais dans ce réseau, le rôle des Britanniques était encore plus prééminent, notamment celui de l'envoyé à Naples William Hamilton qui devint l'un des amis et correspondants les plus proches de Šuvalov.

\section{William Hamilton}

À notre connaissance, la première lettre adressée par Hamilton à Šuvalov date de l'année 1768 :

A present que nous sommes tranquilles je n'oublierai pas de faire en sorte que Kaunitz vous envoye bientôt votre exemplaire d'Herculanum. Le duc de Noya mourut hier au soir, il y aura des belles choses à vendre et malheureusement je n'ai pas beaucoup d'argent, ayant dépensé dans ces fêtes et la peur que j'ai est que ma cour étant pauvre aussi ne me donnera rien pour mes dépenses. Je viens d'écrire à d'Hancarville de vous envoyer le dessein du camée. ${ }^{35}$

Ce à quoi Šuvalov répondit par la suivante :

$\mathrm{Mr}$ et Me de Cour qui me chargent de vous dire mille belles choses de leur part quittent Rome demain, ils soupent chés moi aujourd'hui au jardin sur les cendres d'Auguste. J'ai pris cette maison. Je crois qu'elle n'est point échappée à votre curiosité par sa célébrité. Je n'ai point reçu encore de Mr Danquerville ${ }^{36}$ le dessin de Bacus. La forme d'Apollon est finie, il faut seulement la faire bien secher, et jetter le platre pour vous l'envoyer. Oserai je vous prier Monsieur de me marquer s'il y a quelque chose après le duc de Noya, qui puisse convenir pour le cabinet de l'Impératrice. Je vous ferai parvenir la somme necessaire trop persuadé que l'aquisition que vous voudrés faire meritera sa satisfaction. Encore une prière à vous faire. Je sais que l'homme que vous protegés et qui montre les raretés d'Herculanum, a toutes les meilleures formes des bronzes de cette galerie. Il voulait me les vendre. Si le prix est raisonnable, et la sortie ne souffrira pas de difficultés, je vous prierai de me dire pour que je puisse les acheter. Mr Rasoumowsky et $\mathrm{Mr}$ Nicolay vous presentent leurs respects. Le premier a beaucoup de peine à quitter Rome. Le second désire de revoir les Dieux penates, et de consulter leur oracle sur le voyage qu'il veut entreprendre. Je suis faché qu'il me quitte. Je reste seul des etrangers, dans un païs où l'ancienne urbanité, comme les autres belles choses, se sont perdues. Je m'occupe de mon petit jardin, et de mes commissions. Je brulerai d'impatience de vous revoir. ${ }^{37}$ 
Cette lettre qui, avec les onze autres écrites par Šuvalov à Hamilton et conservées à la Bibliothèque nationale de la Russie à Saint-Pétersbourg, reste inédite, témoigne à quel point le rôle de gentleman-antiquaire réussissait à Šuvalov. Tout d'abord, il s'agissait pour les deux hommes d'échanges de services, de renseignements, de dessins, de copies, de moulage etc. Mais il s'agissait aussi d'un ton commun dominé par une sorte de mélancolie, de mécontentement à l'égard de la vie italienne moderne que partageait cette petite communauté cosmopolite plongée dans le passé. Le choix d'une maison dans un quartier riche de références archéologiques participait à ce sentiment. De même que Gaspare Santini $^{38}$, Šuvalov aurait donc habité dans le Palazzo Valdina ${ }^{39}$, au numéro 22 de l'actuelle via dei Prefetti. Ce palais se trouve sur les restes du cadran solaire d'Auguste, dans la partie septentrionale du Champ de Mars, entre l'Ara Pacis, d'une part, et le Mausolée et l'Ustrinum d'Auguste, d'autre part, ensemble architectural ayant servi lors de son incinération ${ }^{40}$.

Ainsi la mention par Šuvalov des cendres d'Auguste n'était pas fortuite: ce Russe choisissait sa maison en examinant le plan de la Rome antique !

Cette maison resta dans la mémoire des ses amis. En 1778, Kaunitz se souvenait :

Habitant du tombeau d'Auguste, vous sortiez quelquefois de vos décombres pour venir admirer la belle nature dans le délicieux climat de Capoue, la contempler dans les horreurs du Vésuve. ${ }^{41}$

Dans ses lettres, Šuvalov remerciait souvent Hamilton de l'accueil que celui-ci réservait aux Russes et se plaignait du fait que ces derniers s'occupaient davantage d'amusements que d'observations savantes, ce qui n'était certainement pas son cas. Durant ses séjours à Naples, Šuvalov fut en effet parmi les premiers Russes à visiter les fouilles de Pompéi et parmi les premiers Européens à en donner, en 1769, une description qu'il envoya à Golicyn, ambassadeur à Vienne ${ }^{42}$. Les ruines de cette ville y furent non seulement décrites, mais également conjecturées :

Une petite colonnade de pierres communes et peintes en differentes couleurs regne vis a vis les dites maisons et forme un quarré plus etroit. Près de la, est un petit temple et Autel, qui servoit apparemment au culte de quelques particuliers. Tout y est en stuc, mais fort petit. Sur l'Autel sont encor les cendres des victimes. Dans le sanctuaire sont les conduits pour les Oracles et Mysteres.

Les dimensions des maisons pompéiennes le surprirent, ainsi que leur distribution :

Les maisons sont singulierement petites, meme celles qui ont quelques apparences, dans lesquelles on a trouvé des mosaïques et des peintures. On remarque encor qu'il n'y a presque pas de chambre qui ait des fenetres, et l'on ne sait pas trop bien, comment le jour pouvoit y entrer. Tous les toits sont brulés et tombés.

Mais des passions antiques, les deux hommes passaient rapidement aux affaires politiques. En 1770, Šuvalov écrivait à Hamilton :

M. Orloff m'a prié de vous assurer Monsieur dans les termes les plus forts du sentiment de son estime et du respect qu'il vous doit. Si il y aura un consul à Naples, c'est celui qui sera recommandé de vous. ${ }^{43}$

Et à Šuvalov de suggérer l'éventuelle possibilité pour Hamilton de se rendre en qualité d'ambassadeur britannique à Saint-Pétersbourg :

Dites moi cher Seigneur si vous n'abandonnés pas Naples. N'irés vous pas à Vienne ou à Petersbourg. Donnés la preference à nous. Vous serés partout bien ; mais il nous est permis de souhaiter ce qui doit etre agreable à S.M. Impériale. Independemment de vos affaires politiques, vous trouverés une Souveraine aimant et protegeant les arts. On aura besoin de vos conseils et de vos lumieres. Moi qui 
n'aspire que de vivre tranquillement ches moi et d'aller quelques fois à l'hotel de Hamilton presenter mes respects à $M$. l'ambassadeur et à Madame l'ambassadrice, jouir de leur aimable société, admirer leurs vertues, de m'amuser dans leur compagnie, il me semble que cela doit etre. Il faut un peu de la bonne volonté de votre part. Je suis sur que Madame voudra bien vous faire cet honneur et je suis sur aussi que notre climat lui sera favorable. ${ }^{44}$

38

L'amour des arts et les affaires politiques alimentaient pareillement l'amitié d'égal à égal des deux hommes, un ambassadeur en titre et un particulier en exil.

D'autres Britanniques, tels Thomas Jenkins et Gavin Hamilton, peintres, collectionneurs et marchands d'antiquités, furent impliqués dans les affaires romaines de Šuvalov. À Jenkins, Šuvalov achetait les statues antiques. En 1782, lors de son voyage romain, ce fut également à Jenkins que le grand-duc Paul, sans doute conseillé par Šuvalov, acheta des sculptures pour Pavlovsk. Aussi bien Jenkins que Gavin Hamilton étaient, comme il est bien connu, liés à Piranesi. Gavin Hamilton en devint l'associé lors des fouilles à la Villa Adriana entre 1769 et 1771, qui alimentèrent les collections d'antiquités de l'Europe entière. Son nom figure à maintes reprises dans les inscriptions des planches des Vasi à propos des objets découverts lors de ces fouilles. Comme on l'a déjà vu, la première planche du premier volume de la collection montre le vase Warwick trouvé par Gavin en 1771 à cet endroit et vendu au lord William Hamilton, vase qui permet à Piranesi de prôner, une fois de plus, «la perfection des arts au siècle d'Adrian ». D'autres représentants des élites britanniques, dont les noms figurent sur les planches des Vasi, profitèrent de ces fouilles: trente-cinq objets représentés dans les deux volumes se trouvaient à l'époque dans vingt-cinq collections britanniques.

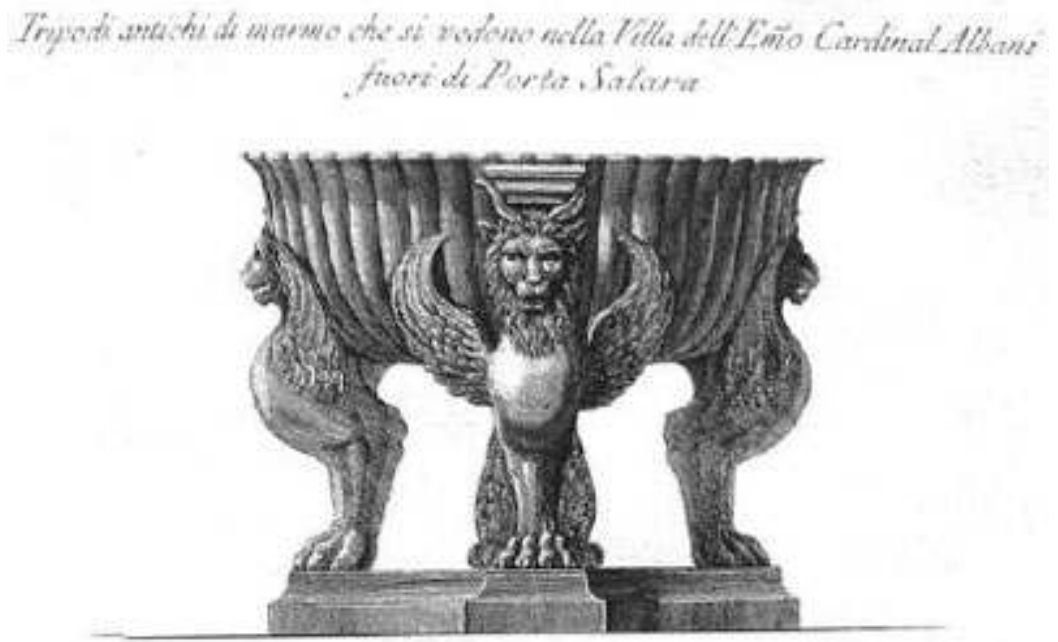


III.2 - Giovanni Battista Piranesi, Vasi, Candelabri, Cippi, Sarcofagi, Tripodi, Lucerne, Ed Ornamenti Antichi..., Roma, v. 1778, tome premier, «Tripodi antichi di marmo... A Sua Eccellenza il Signor Betsky... ». BINHA

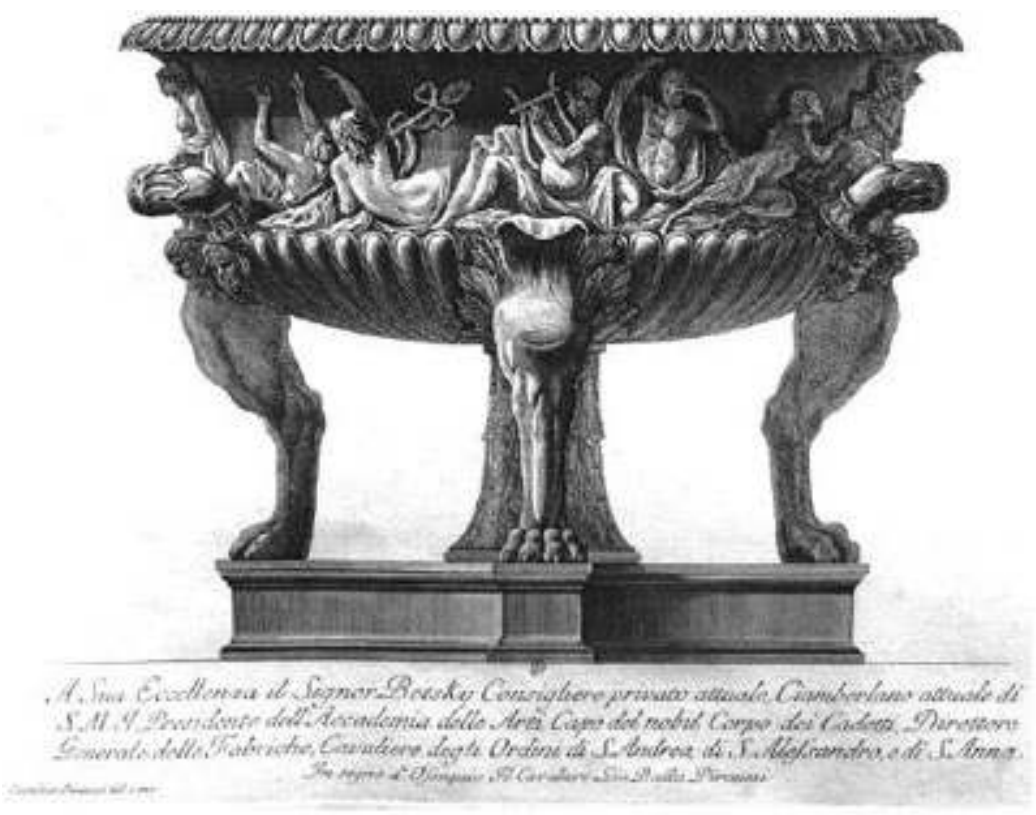

Mais les Russes en profitèrent aussi. À part Šuvalov, dont le nom apparaît dans les volumes des Vasi à cinq reprises et, comme on le verra, aux endroits stratégiques, celui d'Ivan Betskij qui avait remplacé Šuvalov à la tête de l'Académie des beaux-arts de Saint-Pétersbourg, y prit également place et non pas par hasard ${ }^{45}$. [ill.2] La dédicace à Betskij, sans doute suggérée par Šuvalov, ne pouvait signifier que la reconnaissance de Piranesi à l'achat, par l'Académie russe, de « six exemplaire complets de tous les travaux du Saigneur Piranesi aussi bien anciens que nouveaux $»^{46}$.

\section{Les Italiens et Piranesi}

Les Italiens n'étaient pas les plus nombreux dans le réseau de Šuvalov, mais certains d'entre eux furent très importants dont, en premier lieu, le cardinal Alessandro Albani (1692-1779) qui domina pendant un demi-siècle le monde international des collectionneurs et des savants antiquaires romains ${ }^{47}$. Le célèbre Ferdinando Galiani compta également parmi ses relations ${ }^{48}$. Une amitié commune pour le bailly de Breteuil liait les deux hommes. On connaît le rôle que joua Ferdinando, en 1776, dans l'achat par Catherine II de la célèbre bibliothèque de son frère ${ }^{49}$. À l'époque, Šuvalov était déjà de retour à Pétersbourg où il devint l'un des principaux conseillers artistiques de l'impératrice. Nous devinons facilement le rôle qu'il a pu jouer dans cette affaire.

Nombre d'artistes et de restaurateurs italiens furent employés par Šuvalov, tel Bartolomeo Cavaceppi, restaurateur des collections d'antiquités du cardinal Albani et de celles du Museo Capitolino. Au moins cinq bustes de la collection de Šuvalov, rachetée en 1784, après la mort de ce dernier, par Catherine II, qui se trouvent aujourd'hui à l'Ermitage sont des pièces restaurées par Cavaceppi..$^{50}$ Notons que Šuvalov lui-même pratiqua, une fois au moins, une « restauration » digne de Cavaceppi : après avoir acheté une statue de Vénus « avec une tête de valeur médiocre il la remplaça par une excellente tête qu'il acheta. $»^{51}$ 
43 À l'élève de Cavaceppi Carlo Albaccini, Šuvalov acheta une statue de marbre Amour et Psyché, que Jenkins voulut lui racheter car, selon Šuvalov, il la croyait plus belle que celle du Capitole. Le peintre Domenico d'Angeli, futur décorateur de la Villa Borghesi, vendit à Šuvalov " une idole égyptienne en marbre noir», qui provenait de la Villa Adriana à Tivoli $^{52}$. À la même époque, Šuvalov commença à envoyer à l'Académie des fragments antiques - des statues, des vases, des colonnes et des tables de marbre de sortes et couleurs différentes, mais aussi de porphyre ${ }^{53}$ - y compris, par exemple, les deux colonnes provenant du Panthéon. Ces achats semblaient suivre de près l'exemple de Piranesi, amassant les antiquités et incitant les élites européennes à créer des décors à l'antique mélangeant le vrai et le faux.

Dans ce réseau d'artistes italiens que Šuvalov fréquenta, Piranesi avait, en effet, une place de choix. Šuvalov fut l'un des premiers et des plus actifs « agents » de Piranesi à favoriser la distribution de son œuvre en Russie. À part l'œuvre gravée achetée par l'Académie russe, Piranesi, collectionneur et marchand, vendit à Šuvalov plusieurs pièces de son Museum $^{54}$. L'un des vases en marbre représentant les «Fatti d'Ercole» figurait, par exemple dans le recueil des Vasi, comme appartenant à Šuvalov ${ }^{55}$. [ill.3] La dédicace que Piranesi offrit à Šuvalov - et que nous avons mentionnée au début de cet article témoignait donc clairement de sa profonde satisfaction à l'endroit de l'aristocrate russe.

\section{Au service de la cour}

Par ailleurs, douze volumes de Piranesi furent achetés par Šuvalov pour Catherine II sans doute pour être distribués dans son entourage - de sorte qu'elle pouvait écrire plus tard à Grimm : "A présent Piranèse est très à la mode ${ }^{56}$. Servir son impératrice fut en effet l'un des principaux buts de l'ex-favori en exil. Dès 1768, Catherine fut instruite des activités de Šuvalov à Rome. Désespérée par ses commissionnaires ${ }^{57}$, elle surpassa sa réticence vis-à-vis de son ancien adversaire et s'adressa à lui ${ }^{58}$. Il en fit immédiatement part à ses amis parisiens. Ainsi Mme Geoffrin pouvait lui écrire à Rome : "Je suis bien aise Mr le comte, que vous le soyez aussi des commissions qu'elle vous donne; elles sont de votre gout puisqu'elles ont rapport aux arts que vous connoissez, et que vous aimez: étant à Rome vous êtes dans le centre. $»^{59}$

Dans les archives inédites du cabinet de Catherine II, nous avons trouvé plusieurs mentions de payements envoyés à Rome pour le compte de Šuvalov directement de la part de l'impératrice. Ainsi, le 21 octobre 1770, une somme de 146 thalers fut payée au marchand Kreter pour «les statues et les vases reçus de Livourne de la part d'Ivan Ivanovič Šuvalov ». Dans le même fonds, nous trouvons également une correspondance concernant d'importants achats de marbres d'Italie ${ }^{60}$, ainsi que le registre de l'un des envois de Šuvalov adressés à l'impératrice ${ }^{61}$ Y figurent un portrait de l'impératrice exécuté en mosaïque, des tableaux modernes («sept tableaux encadrés sous verre presque tous de la même grandeur, dont l'un est une Crucifixion par Titien et les six autres, des perspectives de la main de Canaletto »), divers objets curieux (statuettes en coquillages et en carapace d'écrevisses) et des naturalia (des pierres de Vésuve). Mais l'essentiel est composé d'antiquités: petits bronzes, médailles, monnaies, miroirs et, enfin, une quantité importante de « diverse vaisselle de maison en argile recouverte de vernis noir $»^{62}$. S'agissait-il là d'une collection de vases, amassés sur l'exemple de William Hamilton? 
III.3 - Giovanni Battista Piranesi, Vasi, Candelabri, Cippi, Sarcofagi, Tripodi, Lucerne, Ed Ornamenti Antichi..., Roma, v. 1778, tome second, « Vaso antico di marmo presso... Gen [era]le Schouvaloff rappresentante i Fatti d'Ercole... », BINHA

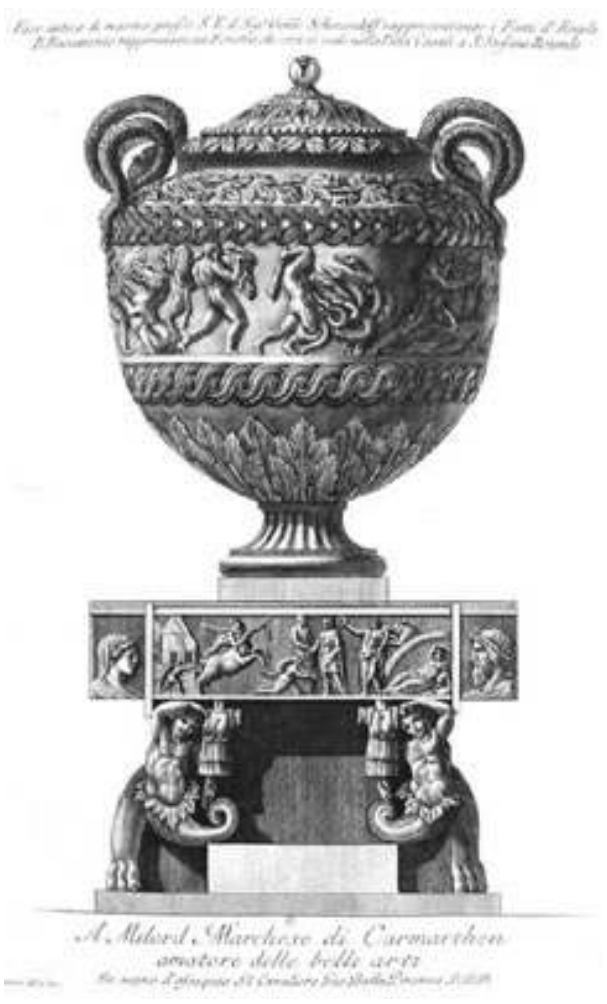

D'autres renseignements nous sont fournis par l'Archivio di Stato qui détient une série de registres de la Camera Pontificia avec notamment les licences obtenues par Šuvalov pour l'exportation d'œuvres d'art, parmi lesquelles le nombre d'antiquités croissait d'année en année ${ }^{63}$.

\section{Pour la gloire de l'Académie}

Si donc le rôle que Šuvalov jouait à Paris était celui d'un homme privé, à Rome il se donna de l'importance en agissant en qualité d'agent artistique de l'impératrice et de l'Académie des beaux-arts. D'ailleurs, dès 1768, il fut élu membre honoraire à l'Accademia di San Luca et conserva ce statut jusqu'en 1795, avec la mention de " attuale Presidente dell'Accademia delle Belle Arti ", alors que ce poste était depuis longtemps occupé par Betskij ${ }^{64}$. La correspondance de Šuvalov avec l'Académie de Saint-Pétersbourg ${ }^{65}$ reflète ses préoccupations. En utilisant les relations privilégiées qu'il avait avec le pape, il se chargea notamment, peu après son installation à Rome, d'envoyer à Saint-Pétersbourg une importante collection de copies de sculptures antiques ${ }^{66}$. La liste de ces moulages, " emportés de la ville italienne de Civitaveccia en 1769, pour l'Académie impériale des Beaux-Arts sous la protection de Ivan Ivanovič Šuvalov », est conservée dans les archives de l'Académie ${ }^{67}$.Les moulages envoyés par Šuvalov et exécutés par Bartolomeo Matavelli, Antonio Giuliani et Alessandro Mazzoni, provenaient de collections diverses parmi les plus appréciées au milieu du xviiie siècle par les connaisseurs de l'antiquité. Y figuraient les collections Farnèse, Médicis et Ludovisi, celles du Capitole et du Vatican, ainsi que de l'Académie de France à Rome. Sur cinquante-huit moulages, deux seulement étaient d'après les modernes: les deux Bacchus de Michel-Ange et de Sansovino. Parmi 
les antiques, on retrouvait l'Hercule Farnèse, Castor et Pollux et le Faune au chevreau, le Camille du Capitole, le buste de Brutus (tête de Lucius Junius) du Capitole, la Vénus callipyge (de la collection Farnèse), le groupe de Niobé, le Faune dansant, Marsyas, Pan et Apollon, Mercure, l'Apollino (de la collection des Médicis), le groupe du Laocoon, la Cléopâtre, le torse du Belvédère (tous les trois du Vatican), Amour et Psyché, le Gladiateur mourant, Flore, Junon, le Faune en marbre rouge, Antinoüs, les Centaures Furietti (du musée du Capitole), les deux pieds et la tête du cheval de la statue de Marc Aurèle, Poetus et Arria, Electre et Oreste, le Mars Ludovisi (de la collection Ludovisi), enfin, le Faune, les Lutteurs et la Vénus Médicis (des Offices) et, pour finir, le célèbre vase Médicis. Ces moulages de très grande qualité se trouvent toujours au musée de l'Académie des beaux-arts de Saint-Pétersbourg.

Outre cela, Šuvalov s'occupait des pensionnaires académiques en Italie, leur procurait des commandes, obtenait pour eux un accès libre aux meilleures collections d'antiquités, y compris à l'Académie de France ${ }^{68}$. À la même époque, Šuvalov réfléchissait au projet de fonder à Rome une académie russe. Bien que ce projet ne semblât pas intéresser Betskij, la «cause » de Šuvalov ne fut pas entièrement perdue. Ce fut sans doute sous son influence que l'Académie introduisit, précisément en 1770, la règle selon laquelle tous les pensionnaires devaient séjourner obligatoirement à Paris et à Rome ${ }^{69}$.

Dans sa lettre du 17 avril 1770, Šuvalov demandait, une fois de plus, une prolongation du séjour romain - contre le séjour parisien - pour les pensionnaires russes : « Je considère le temps de sept mois trop court pour leurs études $»^{70}$. Et il remerciait ainsi l'Académie pour la prolongation obtenue :

En [leur] accordant cette faveur [...] l'Académie des arts sera satisfaite par leurs succès; ce sont tous des gens appliqués et de bonne conduite, et ils sauront utiliser le temps qui leur est imparti à Rome pour leur bien. L'école des arts grecque est très différente de l'école parisienne, ils regrettent probablement de rester si longtemps sous la coupe de cette dernière et de se former insensiblement au goût français dans les arts, que les connaisseurs et même les Français qui se trouvent ici n'approuvent point. ${ }^{71}$

51 Dans la même lettre, il proposait une personne qui pourrait le remplacer quand luimême ne serait plus à Rome pour s'occuper des pensionnaires et des commandes académiques. Il s'agissait de Johann Friedrich Reiffenstein.

\section{Reiffenstein}

52 Šuvalov rencontra Reiffenstein pas plus tard qu'en 1768. Ce fut en tout cas au mois d'octobre de cette année-là qu'il lui suggéra de se présenter en qualité d'agent à l'Académie des beaux-arts de Saint-Pétersbourg. Dans sa lettre à Šuvalov, datée du 21 octobre, Reiffenstein ébauchait dans ce but son autoportrait :

Penetré de la plus vive reconnoissance envers les marques distinguées de la protection dont Votre Excellence continue de m'honorer j'obéis aux gracieuses ordres qu'elle vient de me donner de déclarer plus positivement, au quel genre de service je me trouverai le plus capable et plus disposé, en cas que j'aspirais à l'honneur d'être appellé aux services de Sa Majesté l'Impératrice de la Russie. Votre Excellence aura déjà observé elle-même pendent le temps que j'ai eu l'honneur de lui faire ma cour que tous mes talents et inclinations roulent sur la connoissance et la pratique des Arts qui dépendent du Dessein, et des études qui y sont relatives. En cela toute ma capacité est bornée de manière si on m'ôte de cette sphere, je ne suis qu'un homme de lettres ordinaire dont tous les pais abondent. Au 
lieu si je pourrois être emploié dans la sphere de mes talens et connoissances que j'ai eu occasion de cultiver le plus, je pourrois peut être rendre des services plus utiles et plus particulières dans ce genre que plusieurs autres qui n'ont pas eu l'avantage de séjourner et d'étudier un temps considerable dans le Pais ou les beaux arts sont le plus cultivés.

Je me trouve extremement porté d'encourager le progrès des beaux arts dependent du Dessein, et d'inspirer aux artistes l'ardeur de se perfectionner dans la manière des anciens grands maîtres. En travaillant avec eux, je me suis acquis partout leur affection et leur confiance, et ils m'écoutent avec une complaisance plus marquée que ces amateurs ordinaires, qui ne manient pas eux même ni le craion ni le pinceau avec quelque succes et je me suis apperçu que ma conversation est devenue utile à plus d'un artiste et j'ai inspiré à plusieurs l'ardeur de tendre vers la perfection dans leur art. $»^{72}$

Reiffenstein se présentait en qualité de connaisseur qui avait des compétences théoriques et pratiques si rares et exclusives qu'il pouvait participer au progrès des beaux-arts à travers la simple conversation avec les artistes. Il se proposait donc de prendre sous sa protection les pensionnaires russes en promettant de deviner parmi eux « des jeunes Raphaëls et des Dominiquins " qui naissaient selon lui sous tous les climats ${ }^{73}$. Il s'étonnait néanmoins que cela ne lui valait pas une pension aussi importante qu'il espérait et, pour l'augmenter, se proposait également en qualité d'agent :

[...] la connoissance que je me suis acquise des differents ouvrages de Peinture et Sculpture tant ancienne que moderne, et la confiance et l'amitié avec les Meilleurs Artistes et plusieurs Savans de Rome me mettroit de même en etat de veiller aux Interets de Sa Majesté Impériale et de la Nation en cas des commissions chez les Artistes à Rome ou à l'occasion de quelque achat des Ouvrages soit antiques soit modernes et de tout ce qu'il seroit du Ressort d'un Agent au moins dans le departement des Arts et de la litterature. ${ }^{74}$

Cette pension lui était indispensable pour prolonger son séjour en Italie ainsi que ses recherches dans le domaine des techniques artistiques antiques

surtout celle sur les Camées, bas-relief et Vases en Pate pour lesquels S.E. déjà s'est si généreusement intéressée Elle-même, pour faire revivre enfin dans son entier cet Art des Anciens et pour produire quelque chose digne d'être mis aux Pieds de Sa Majesté Impériale et utile en même temps à l'état par une nouvelle branche d'un commerce assez considérable de ce que l'usage de ces ouvrages sera introduite. ${ }^{75}$

55 La mention de l'intérêt que Šuvalov manifesta pour les recherches menées par Reiffenstein est très parlante. Il s'agissait d'un «intérêt généreux ", c'est-à-dire, sans doute, d'un financement important de la part du Russe.

De son côté, dans ses lettres envoyées à Betskij, Šuvalov louait Reiffenstein et décrivait ses qualités exceptionnelles. En présentant Reiffenstein à l'Académie de SaintPétersbourg, Šuvalov le caractérisait comme " un homme de grand savoir en matière d'arts », le meilleur qu'on pût trouver, et « de plus un homme bon et honnête " ${ }^{76}$. Il pouvait donc s'occuper des pensionnaires, mais aussi aider dans les achats de tous genres et l'embauche des artisans. Enfin, écrivait Šuvalov, il « grave, peint, fait des modèles et

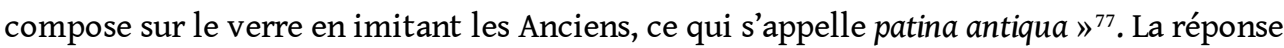
favorable de l'académie prévoyait pour Reiffenstein le titre de membre-amateur qu'il pouvait obtenir à la présentation d'une " lettre d'intention », comme tous les autres ${ }^{78}$.

À l'assemblée générale tenue le 9 janvier 1771, l'Académie des beaux-arts de SaintPétersbourg attribua à Reiffenstein non seulement le titre d'académicien honoraire, mais également celui de "Son Commissionnaire pour ce qui concerne les Arts et les Eleves Pensionnaires qu'Elle a envoiée et qu'Elle continuera d'envoier à Rome», avec une 
pension de deux cent scudi par $\mathrm{an}^{79}$. Dans sa lettre de remerciement envoyée aux académiciens le 26 avril 1771, Reiffenstein rendait, une nouvelle fois, hommage à son protecteur:

Je m'estime heureux que cela se pourra faire sous les auspices et les ordres de S.E. Monsieur le General de Schouvalov, à la favorable recommendation duquel je dois l'honneur que l'Académie Imperiale vient de m'accorder et je me flatte qu'il daignera d'être temoin de ma bonne volonté et de mon zêle pour m'acquitter au mieux de ces devoirs..$^{80}$

Ce choix de Reiffenstein fut l'une des plus belles intuitions de Šuvalov. Comme en témoigne notamment sa correspondance avec l'Académie, jusqu'à sa mort en 1793, Reiffenstein s'occupa des pensionnaires, réglant leurs dettes, leur trouvant des logements et des professeurs (tels que Batoni et Mengs), leur obtenant un accès libre à l'Académie de France à Rome ainsi que dans les différentes galeries privées (telles que les galeries Corsini et Giustiniani). Les rapports des pensionnaires qui étudièrent à Rome sous la houlette de Reiffenstein ${ }^{81}$ sont très instructifs de ce point de vue. Mais leurs productions romaines le sont encore davantage : des copies d'après l'antique ou d'après les œuvres de la Renaissance, des paysages avec ruines... Ces derniers, de même que les dessins des architectes, trahissaient une forte influence de Piranesi auquel, par ailleurs, l'Académie de Saint-Pétersbourg proposa de délivrer un diplôme de membre libre honoraire ${ }^{82}$.

\section{Du vase Warwick au vase Médicis}

Mis à part le frontispice du second volume que nous avons signalé au début de cet article, deux gravures dédicacées à Šuvalov furent placées, dans les deux volumes des Vasi, à des endroits stratégiques. Étant donné que dans la plupart des exemplaires de ce recueil que nous avons consultés, cet emplacement ne varie pas, nous pouvons en déduire un geste conscient de l'artiste. Ce serait un argument de plus pour attribuer à Piranesi la conception générale du recueil.

60 La première gravure représente le vase Borghèse (actuellement au musée du Louvre) décoré d'une scène de bacchanale (ill. 4). Suivie de la représentation du relief qui le décore, elle clôt le premier volume. La seconde, qui clôt le second volume, représente le vase Médicis montrant le sacrifice d'Iphigénie (actuellement au musée des Offices à Florence) (ill. 5-6) ${ }^{83}$. La gravure représentant le bas-relief avec la scène du sacrifice, "découpée » du vase, porte une longue inscription qui narre en détail l'histoire d'Iphigénie. À la différence de la plupart des pièces qui figurent dans le recueil des Vasi, ces vases dédicacés à Šuvalov, ne relevaient pas des découvertes récentes. Ils n'étaient pas non plus à vendre et se trouvaient, tout au contraire, parmi les pièces les plus réputées et les plus copiées à travers l'Europe. Šuvalov lui-même avait d'ailleurs envoyé à l'Académie les moulages des deux vases qui décorent encore aujourd'hui le hall central du bâtiment académique élevé par Vallin de la Mothe, alors que deux autres copies ou moulages se trouvent à l'Ermitage.

61 Le choix pour Šuvalov de ces deux vases était-il innocent ? Existe-t-il un lien entre la dédicace à Šuvalov et le relief du vase Médicis? 
III.4 - Giovanni Battista Piranesi, Vasi, Candelabri, Cippi, Sarcofagi, Tripodi, Lucerne, Ed Ornamenti Antichi..., Roma, v. 1778, tome premier, « Vaso antico di marmo di gran mole che vedesi nel Palazzo della villa Borghese... A Sua Eccellenza il Sig-r. General Schouvaloff... ». BINHA

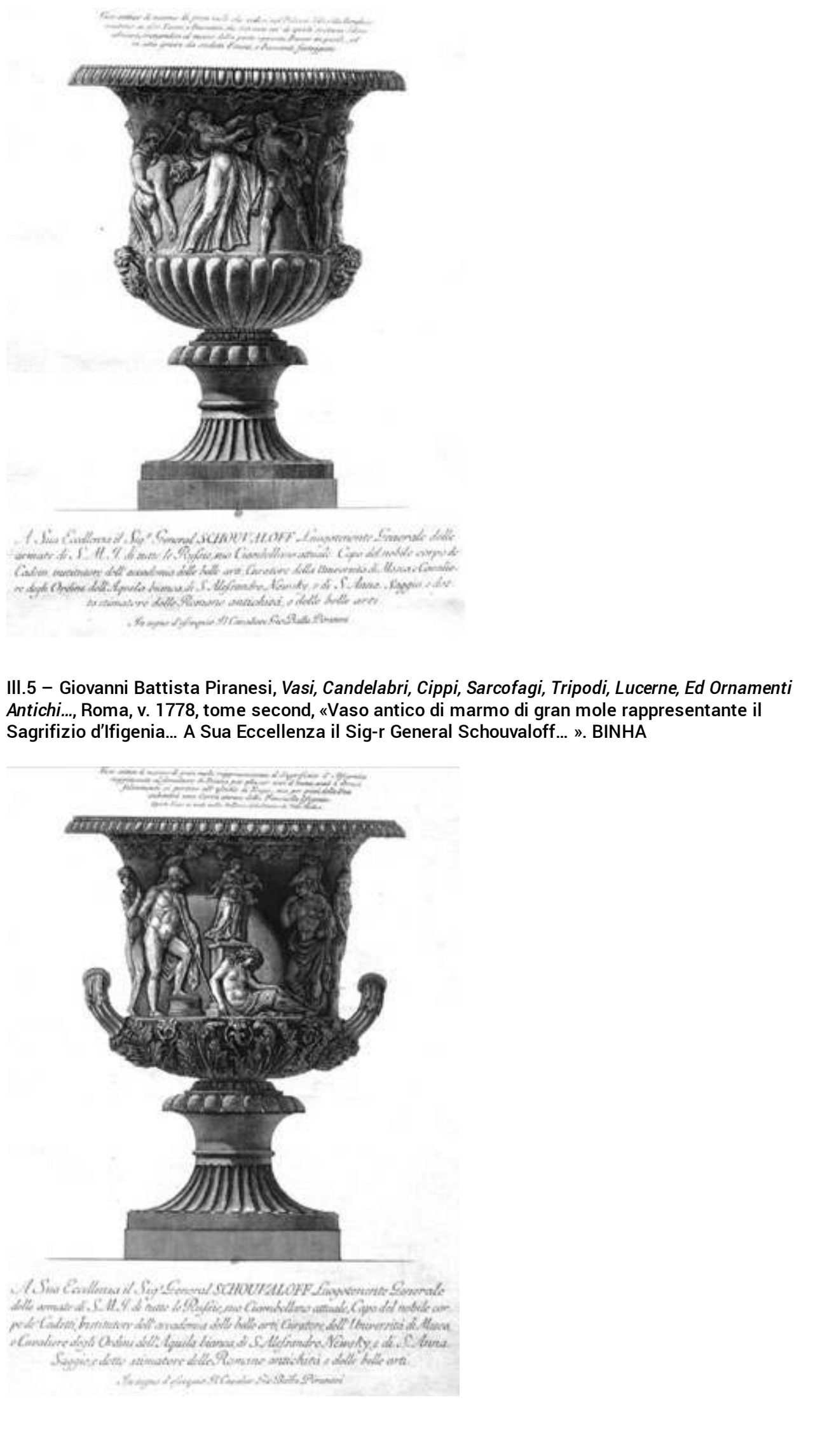


III.6 - Giovanni Battista Piranesi, Vasi, Candelabri, Cippi, Sarcofagi, Tripodi, Lucerne, Ed Ornamenti Antichi..., Roma, v. 1778, tome second, «Basso Rilievo, il qual'è scolpito sulla Circonferenza del

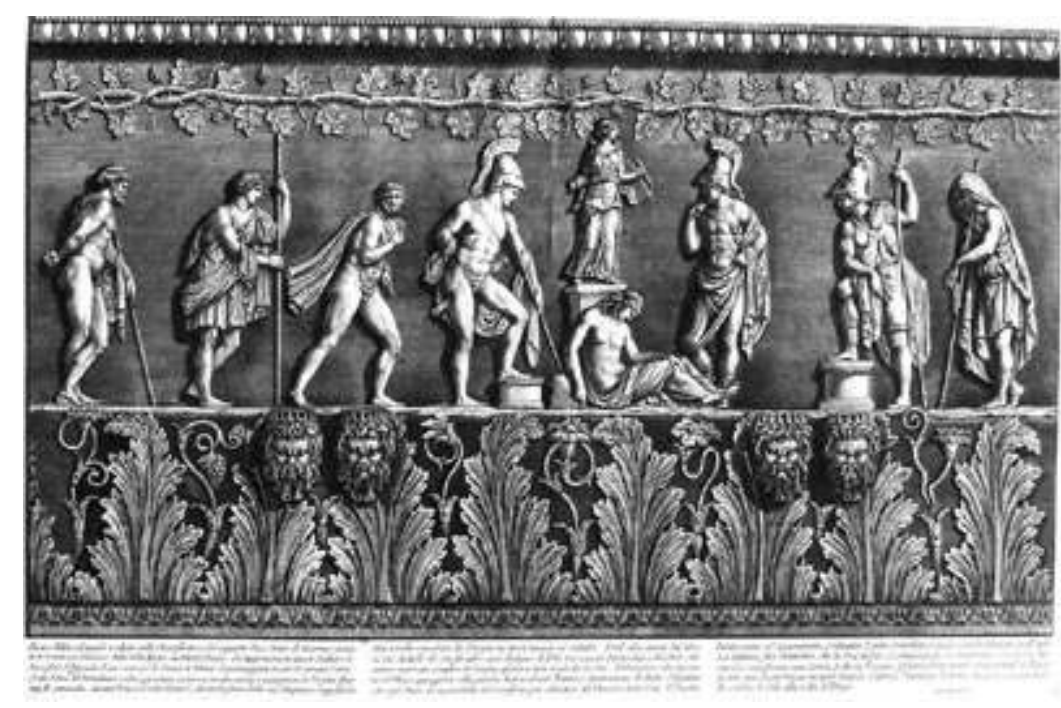

Tout d'abord, l'emplacement des planches dédicacées à Šuvalov dans les deux volumes $\mathrm{du}$ dernier recueil piranesien nous semble parlant, ceci d'autant plus que nous connaissons l'importance de la dédicace pour Piranesi ${ }^{84}$. Les élites russes, fraîchement occidentalisées, représentantes du monde nouveau, avides d'imiter les Européens, venaient de se joindre aux grands touristes. Elles ouvraient des horizons nouveaux et constituaient des clients par excellence pour les marchands d'antiquités. Étant donné que l'exportation des grandes pièces devenait de plus en plus difficile, il s'agissait surtout de "petites" pièces ou de fragments (y compris des «morceaux » d'architecture) qui pouvaient servir sur place à créer des décors à l'antique, comme ceux proposés par Piranesi dans les planches de ses Diverse maniere d'adornare i cammini (Rome, 1769) Ces décors étaient considérés par Piranesi lui-même ainsi que pour ses clients les plus importants, tel William Hamilton, comme faisant partie d'un grand projet civilisateur. Ainsi les Vasi s'ouvraient, comme on l'a déjà vu, par le vase Warwick, dont le piédestal portait l'inscription « in patriam transmissum/ patrio bonarum artium genio dicavit $»^{85}$, et se terminaient par le vase Médicis dont le sujet, doublé par la dédicace à Šuvalov, renvoyait à l'impératrice russe elle-même. C'est elle, selon nous, qui figurait sous les traits d'Iphigénie.

\section{Le sacrifice d'Iphigénie}

Le 18 octobre 1771 Voltaire écrivait à Frédéric :

L'impératrice de Russie dit que ses affaires vont fort bien par delà le Danube ; qu'elle est maîtresse de toute la Valachie, à une ou deux bicoques près; qu'elle est reconnue de toute la Crimée. Il faudra qu'elle fasse jouer incessamment, sur le théâtre de Batchi-Saraï, Iphigénie en Tauride. Puisse-t-elle faire bientôt une paix glorieuse, et puissent ces vilains Turcs ne plus molester les chrétiens grecs et latins!

La mention d'Iphigénie reparaissait dans une lettre que le prince de Ligne - dans la suite de Catherine II en Crimée - adressait à la marquise de Coigny : 
C'est sur une rive argentée de la mer Noire; c'est au bord du plus large des ruisseaux où se jettent tous les torrents du Tezzeterdan; c'est à l'ombre des deux plus gros noyers qui existent, et aussi anciens que le monde; c'est au pied du rocher où l'on voit encore une colonne, triste reste du temple de Diane, si fameux par le sacrifice d'Iphigénie, c'est à gauche du rocher d'où Thoas précipitait les étrangers ; c'est enfin dans le plus beau lieu et le plus intéressant du monde entier, que j'écris ceci. ${ }^{86}$

Sujet homérique repris par Euripide, l'histoire d'Iphigénie fut très en vogue tout au long du xviiie siècle. Revisité dans De rerum natura de Lucrèce, ce sujet - en fable exposant les méfaits de la superstition, voire de la religion (Tantum religio potuit suadere malorum) ${ }^{87}$ - fut particulièrement apprécié au siècle des Lumières. Il le devint encore davantage et prit une connotation politique à compter de la conquête par Catherine II de la Crimée, qu'en Russie on nommait alors couramment "Tauride " (ainsi le nom du prince de Tauride fut donné à Potemkin) et qu'on associait constamment à l'antiquité grecque. En occupant la Crimée, Catherine ne gagnait pas seulement l'accès à la mer, elle « rendait " également aux Russes « leur» Grèce, à la fois antique et byzantine ${ }^{88}$. La célèbre statue de Vénus achetée par Pierre le Grand en 1718 au pape Clément XI, fut alors placée au palais de Tauride de Potemkin et reçut le nom de la Vénus de Tauride, incarnant l'antiquité retrouvée par les Russes.

Dans les lettres de Šuvalov à ses amis en Italie, et particulièrement à Hamilton, les mentions des antiquités se mélangeaient avec celles des victoires de l'armée russe en Crimée. En profitant de ses relations, ce cosmopolite menait en effet une véritable propagande prorusse. Ainsi, le 17 avril 1770, il écrivait à Hamilton de Rome :

J'ai l'honneur de vous envoyer l'extrait de la lettre que j'ai reçue de Mer le comte Roumanzoff trop persuadé qu'elle vous fera le meme plaisir que la nouvelle de mer. Ma nation en se distinguant par sa bravoure, son courage et sa capacité méritera de plus en plus d'amitié de la votre. Je n'ai personne ici avec qui partager ma joye. Il y a quelques uns indifférents et tout le reste est porté pour les turbans. Il y a même de ces incrédules qui n'ont pas foi à ces événement : comme le préjugé est plus fort que la raison, plusieurs conservent la meme haine contre les grecs comme du temps du Patriarche Plotius et du Pape Nicolas, on aimerait mieux un Morofti qu'un archevêque grec. ${ }^{89}$

La nuit du 6 au 7 juillet 1770, la flotte russe dirigée par le comte Orlov et l'amiral Greig battit la flotte turque dans le port de Česmé, ce qui décida de l'issue de la première guerre russo-turque. C'est pour célébrer cette bataille que plus tard l'Italien Stefano Torelli peignit son Allégorie sur la victoire de Catherine II sur les Turcs et les Tatares ${ }^{90}$, en représentant Catherine en Minerve, ses généraux en costumes antiques et, dans le fond à gauche, un prêtre en habit orthodoxe rendant un sacrifice devant un temple antique. Le rite orthodoxe de l'église grecque s'y confondait délibérément avec les usages antiques.

Le 24 novembre 1770, Šuvalov s'adressait à Hamilton pour lui demander un service en relation avec cette victoire :

Il s'agit de peindre un tableau de la destruction de la flotte ottomane. J'ai cru que personne ne pourrai mieux réussir à représenter ce spectacle du feu, que le peintre Volaire. Il le fera au mieux. Si vous aurés la bonté de lui communiquer vos idées et le diriger dans son ouvrage. Je vous prie Monsieur de m'accorder cette nouvelle marque de votre bienveillance. Je joins ici une relation imprimée et le plan de la bataille. Il faut faire suivant l'endroit où la flotte fut brulée. Vous aurés la bonté de faire venir ce Volaire et de lui demander s'il veut entreprendre cet ouvrage. De quelle grandeur vous pensés qu'il doit être fait? Il faut plutot grand que petit. A combien cet ouvrage peut monter et quel temps il faut pour le faire. Le plutot sera 
le mieux, et on peut augmenter le prix, pourvu qu'il le fasse vite. Pour ce qui regarde le pavillon des vaisseaux, les uniformes, les principaux personnages qui doivent etre marqués, tout lui sera communiqué. ${ }^{91}$ façon et lui suggérer un sujet lié à la conquête de la Crimée? L'admiration de Catherine pour Piranesi ne pouvait pas lui échapper: comme on l'a vu, ce fut à Šuvalov qu'elle demanda d'acheter plusieurs de ses volumes. Ainsi la nouvelle gravure qui associait les noms d'Iphigénie, de Šuvalov et de Piranesi, pouvait facilement lui parvenir et lui faire plaisir. La gravure dédicacée à Šuvalov fut - de manière elliptique - dédicacée donc à Catherine II, nouvelle Iphigénie (sorte d'Isaacantique au féminin) qui, comme elle dans sa jeunesse, aurait échappé au sacrifice et se serait transformée en prêtresse de Tauride, c'est-à-dire de la Crimée. Ce rôle de vierge-prêtresse lui plaisait fort bien: ce fut ainsi que Catherine se fit représenter par Dimitrij Levitskij, dans un temple antique, sur fond de mer ${ }^{94}$. L'image du sacrifice, rappelant ce à quoi elle avait échappé en écartant son mari du trône, ne devait pas lui déplaire non plus.

(t) Rome en amateur, en se " moulant » au contact des cercles les plus brillants et érudits, Šuvalov saurait donc pressentir, voire influencer, cette forme d'appropriation nationale et politique de l'antiquité qui allait se généraliser à la cour et dans les élites russes des années 1780-1800. C'est à la cour de la Russie et parmi les élites russes que, par ailleurs, de grands travaux décoratifs dans l'esprit des Vasi furent réalisés durant ces années, travaux dirigés par Giacomo Quarenghi, Charles Cameron ou Vincenzo Brenna ${ }^{95}$, directement influencés par Piranesi.

\section{NOTES}

2. Recueil parmi les moins étudiés de Piranesi, Vasi, Candelabri, Cippi, Sarcofagi, Tripodi, Lucerne Ed. Ornamenti Antichi est une collection de 114 planches non-numérotées, réunies 
en deux volumes, chacun avec sa page de titre, qui représentent aussi bien des antiquités issues des fouilles et restaurées en partie par Piranesi lui-même que, davantage encore, des pastiches d'antiquités. À partir de 1767, ces gravures furent publiées et vendues par Piranesi pour attirer l'attention des acheteurs potentiels sur les pièces de son « Museo » au Palazzo Tomati. Le frontispice du premier volume est daté de l'année 1778, année de la mort de Piranesi, mais l'inscription inhabituelle de cette date "MDCCLXXIIX » a permis de supposer qu'elle déguisait la précédente : 1773 . Un corpus avec le (ou les) frontispice(s) avait pu paraître entre 1772 et 1778, avant ou juste après la mort de Piranesi, sans doute conçu par l'artiste et peut-être juste achevé par son fils Francesco. Voir notamment John Wilton-Ely, Giovanni Battista Piranesi: The Complete Etchings, San Francisco : Alan Wofsy Fine Arts, 1994, 2 vol., chap. F. II, vol. II, p. 961-962; Petra Thomas, Giovanni Battista Piranesi als Antikenrestaurator: " Vasi, candelabri, cippi, sarcofagi, tripodi, lucerne ed ornamenti antichi », 1778, Hamburg, 1999, Sarah E. Lawrence, éd., Piranesi as Designer, New York: Copper-Hewitt National Design Museum, 2007 et, surtout, pour l'hypothèse de la datation et de la cohérence de l'ouvrage, particulièrement importante pour notre propos: Early printed books, 1478-1840: Catalogue of the British Architectural Library Early Imprints Collection, t. III, p. 1508-1509.

3. Le titre de "promotore " ne fut employé, dans cette collection, que plus tard, par Francesco, le fils de Piranesi, dans l'inscription de la gravure dédicacée au pape Pie VI.

4. Pour l'histoire de ce vase créé sur le dessin de Piranesi sans doute par Cavaceppi à partir des fragments découverts par Gavin Hamilton aux alentours de la Villa Adriana en 1771, voir: Vases \& volcanoes: Sir William Hamilton and his collection, Londres: British Museum Press, 1996, p. 220-222.

5. En effet, malgré les quelques publications qui lui ont été consacrées depuis une dizaine d'années, la personnalité d'Ivan Šuvalov demeure essentiellement incomprise. Mis à part la complexité réelle du personnage, cette situation s'explique, sans doute, par le caractère trop fragmentaire des sources dont nous disposons, auxquelles les nouveaux témoignages ne s'ajoutent que d'une façon trop disparate et ponctuelle. Notre propre démarche consiste à réunir les sources aussi bien publiées que manuscrites et à les confronter avec les modèles de comportement culturel, en vogue dans l'Europe du milieu du xviii ${ }^{\mathrm{e}}$ siècle.

6. GARF (Gosudarstvennyj arhiv Rossijskoj federacii - Archives d'État de la Fédération de la Russie, Moscou), f. 728, op. 1, n 112, 1. 3-3v, Jean Schouwalov. Sa vie publique et privée sous règnes d'Elisabeth, de Pierre III, et de Catherine II. Ses relations avec les philosophes et les personnes remarquables du 18 siècle suivi de quelques notions sur le commencement du catholicisme en Russie.

7. Voir, par exemple, dans Rovinskij (Podrobnyj slovar' russkih gravirovannyh portretov [Dictionnaire raisonné des portraits gravés russes], SPb.: Imperatorskaja Akademija Nauk, 1886-1889, 4 t.) trois gravures signées par Šuvalov, dont son autoportrait et le portrait d'Elisabeth.

8. Voir le registre de la collection des tableaux, vendue par Šuvalov à Catherine II avant son départ, dans Stählin, Zapiski Jakoba Štelina ob izjaščnyh iskusstvah $v$ Rossii [Mémoires de Jacob Stählin sur les beaux-arts en Russie], M. : Iskusstvo, 1990, t. 2, p. 174-179.

9. RGADA (Rossijskij gosudarstvennyj arhiv drevnih aktov - Archives d'État de Russie des Actes anciens, Moscou), f. 17, e.hr. 303, 1753, « De l'envoi en Italie des élèves en architecture, Lettres à Jurij Kologrivov ». 
10. Voltaire, Histoire de l'empire de Russie sous Pierre le Grand, édition critique par Michel Mervaud, avec la collaboration de Ulla Kölving, Christiane Mervaud, Andrew Brown, Voltaire Foundation, Oxford, 1999. Introduction, t. I, p. 87-373.

11. Les consolations de l'absence, album de copies, RNB (Bibliothèque nationale de Russie), $\mathrm{SPb}$., fr. Q IV n 207, 1. 11v-12. Je conserve, dans toutes les lettres inédites que je cite dans cet article, l'orthographe de l'original.

12. Šuvalov déposa la demande de congé le 9 octobre 1762, trois mois après l'avènement de Catherine II au trône (28 juin 1762).

13. Comme en témoigne l'une de ses lettres qu'il adressa tout au long de son voyage à sa sœur Praskov'ja Golicyn. Voir: Petr Bartenev, «I.I. Shuvalov », Russkaja beseda, n 1, 1875, p. 56.

14. Publiée en partie dans Literaturnoe nasledstvo, t. 29-30, M., 1937.

15. Les consolations de l'absence, 1. 82.

16. Ibid., 1.87.

17. Un autre aspect de sa vie parisienne semble avoir pris de l'importance. Sous l'influence spirituelle du comte Victor-Maurice de Caraman, Šuvalov exprima sa déception devant les idées des encyclopédistes. Dans la célèbre affaire du Chevalier de la Barre, il resta entièrement du côté de l'Église. En 1779, Catherine II écrit à Grimm : « [...] outre cela il est devenu si dévot qu'il ne me proposera point de Vénus de Titien; ce serait un péché ; c'est le comte de Caraman qui l'a fortifié dans l'état de grâce, et cette dévotion n'a pas peu contribué à le rendre perclus, parce que l'été passé il passait à Tsarsko-Selo des nuits entières à prier Dieu à genoux. " Sbornik imperatorskogo russkogo istoričeskogo obščestva [Recueil de la société d'histoire russe impériale], t. 23, p. 124. (Correspondance de Catherine II avec Grimm). Voir la correspondance de Šuvalov avec Camaran, dans Les Consolations de l'absence, 1. 47-67.

18. A. Nivière, «Ivan Ivanovič Šuvalov i ego francuzskie korrespondenty [Ivan Šuvalov et ses correspondants français] ", in Filosofskij vek, n8, Ivan Ivanovič Šuvalov (1727-1797): prosveščennaja ličnost' $v$ rossijskoj istorii [Le siècle philosophique. Šuvalov, homme éclairé dans l'histoire russe], SPb., 1998, p. 178.

19. «Les jardins sont superbes, d'un goût très différent des autres. Dès mon retour, je donnerai l'idée de la façon de planter un jardin semblable à Kimra (village du gouvernement de Tver', qui appartenait à la comtesse A.K. Voroncov). L'art consiste ici à faire en sorte qu'il ressemble à la nature. Il me semble que cela est mieux. » Arhiv knjazja Voroncova [Archives du prince Voroncov], livre 6, M., 1873, p. 304; lettre de Šuvalov à Voroncov, Londres, 10 mai 1765.

20. En juin 1776, Walpole écrivait à Šuvalov à Paris : « Je me flatte, M. le Cte, que vous aurez reçu avant cette lettre une petite caisse de médaillons que j'ai adressée à notre bonne amie de St Joseph. J'ai dépensé tout votre argent, mais la quantité n'est pas inconsidérable et cependant il m'en reste encore deux à vous envoyer, que le marchand avoit oubliés qu'il m'a remise après la caisse partie. Parmi celles que vous avez il y a une tête en profile de Milord Chatam que vous reconnoitrez très facilement. Si vous êtes contents de mes soins, n'oserai-je pas me flatter que vous voudrez bien me faire l'honneur d'être votre commissionnaire. Il me sera bien sensible d'avoir occasion de vous faire souvenir de moi. » Les Consolations de l'absence, 1. 43-44.

21. En avril 1774, Šuvalov revient à Paris et y demeure jusqu'à septembre 1777, année de son retour définitif à Saint-Pétersbourg. 
22. «Pis'ma I.I. Šuvalova k sestre ego rodnoj, knjagine Praskov'e Ivanovne Golicynoj, uroždennoj Šuvalovoj [Lettres de Šuvalov à sa sœur la princesse Praskov'ja Golicyn, née Šuvalov], Moskvitjanin, t. 5, n 10, 1845, p. 149 (lettre du 9 juin 1770).

23. Ibid., p. 150.

24. A.V. Bekasova, « 'Faros mladyh vel'mož' : I.I. Šuvalov i obrazovatel'nye putešestvija rossijskih dvorjan [Šuvalov et le Grand Tour de la noblesse russe], Filosofskij vek, p. 24-34.

25. Voir, la correspondance de Šuvalov avec Razumovskij dans: A.A. Vasil'čikov, Semejstvo Razumovskih [La famille Razumovskij], SPb., t. I, 1880.

26. « Pis'ma I.I. Šuvalova k sestre ego rodnoj, ...», p. 149.

27. D.N. Kostyšin, « Diplomatičeskoe poručenie Ekateriny II I.I. Šuvalovu [Une mission diplomatique confiée à Šuvalov par Catherine II] », Filosofskij vek, p. 115-138.

28. Ibid., p. 175.

29. En 1776, par exemple, Bernis écrivait à Šuvalov qu'il avait reçu de sa part « les deux jeunes comtes de Roumiantzoff ainsi que M. Grimm. Les deux premiers m'ont parû parfaitement bien élevés et M. Grimm un homme fort bien instruit et fort aimable. Ils sont partis pour Naples et retourneront ici le Carême. J'espère qu'ils seront contents de mes attentions pour eux. Je suis en possession d'exécuter vos ordres et de recevoir, comme ils le méritent les gens de qualité de votre nation. » Les consolations de l'absence, l. 22. En 1778, Šuvalov faisait part à Bernis du désir qu'avait l'impératrice d'obtenir les copies des manuscrits « grecs et latins les plus curieux qui se trouvent au Vatican, ainsi que des documens qui peuvent jeter du jour sur l'histoire. » Ibid., 1. 23v.

30. Mc Cormick, J. Thomas, "Piranesi and Clerisseau's vision of classical antiquity ", Piranese et les Français, Collection de l'Académie de France à Rome, 2, Rome: Edizione dell'Elefante, 1978, p. 303-312 ; Gilles Montègre, « Un médiateur culturel français dans la Rome des Lumières: le père François Jacquier, 1744-1788 ", in Olivier Forlin, éd., Anticléricalisme, minorités religieuses et échanges culturels entre la France et l'Italie, P.: L'Harmattan, 2006, p. 181-202, ainsi que l'ouvrage de ce dernier: La Rome des Français au temps des Lumières : Capitale de l'antique et carrefour de l'Europe, 1769-1791, Rome : Collection de l'École française de Rome, p. 435, 2011.

31. Les consolations de l'absence, 1. 30-31.

32. Voir, par exemple : Elide Casati, « La dispersione della raccolta Pertusati e il ruolo di Antonio Greppi », Finanza e politica nell'eta di Maria Teresa: Antonio Greppi, 1722-1799, Archivio Storico lombardo, 1996, v. 13, p. 341-352.

33. Les consolations de l'absence, 1.176.

34. RGADA, f. 1263, op. 1, d. 1135-1136, 1143. Je remercie Wladimir Berelowitch de m'avoir indiqué cette source.

35. Les consolations de l'absence, 1. 33-34.

36. Sur Pierre-François Hugues d'Hancarville voir, par exemple: Jonathan Smith, The Pleasures of Antiquity: British Collectors of Greece and Rome, New Haven: University Press for the Paul Mellon Centre for Studies in British Art, 2003; V. Coltman, «Sir William Hamilton's vase publications (1767-1776): A case study in the reproduction and dissemination of antiquity ", Journal of Design History, 14, 2001, p. 1-16.

37. RNB, Saint-Pétersbourg, Département des Manuscrits, f. 875, Šuvalov, $N^{\circ} 3: 12$ lettres de Šuvalov à W. Hamilton, acheté en 1899 , pour 25 roubles (toutes les lettres écrites et signées de sa main), 1. 2-2v. 
38. Sur Gaspare Santini, voir l'article de Sergej Androssov, in Sergej Karp, éd., Le Siècle des Lumières. I. Espace culturel de l'Europe à l'époque de Catherine II, M. : Nauka, 2006.

39. Je remercie Christoph Frank de m'avoir communiqué les informations concernant cette maison.

40. Lawrence Richardson, A New Topographical dictionary of ancient Rome, Baltimore : John Hopkins University Press, 1992; Edmund Buchner, «De horologio solario Augusti »,Meander, 42, 1987, p. 71-86; Marcel Le Glay, « L'idéologie solaire. Les pharaons. Auguste. Louis XIV», Archeologia, 249, 1989, p. 56-66; Emilio Rodrigez Almeida, «Il Campo Marzio settentrionale. Solarium e pomeriu », RPAA, 51-52, 1978-1980, p. 195-212.

41. Les Consolations de l'absence, 1. 177.

42. RGADA, f. 1263 «Golicyny [Les Golycyn]», op. 1, d. 1136, 1. 29-31v. Je remercie Wladimir Berelowitch de m'avoir indiqué cette source.

43. RNB, Saint-Pétersbourg, département des manuscrits, f. 875, Šuvalov, Nº 3, 1. 8v.

44. Ibid., 1. 6-6v.

45. Il s'agit de la planche qui représente « Tripodi antichi di marmo » qui se trouvent à la villa du cardinal Albani à la Porta Salara. À part les titres officiels de Betskij, aucun titre d'amateur ne lui fut attribué par Piranesi.

46. "Pisma Šuvalova iz Italii s otvetami na nih konferenc sekretarja A.M. Saltykova [Lettres de Šuvalov d'Italie avec les réponses du secrétaire Saltykov]», In P.N. Petrov, Sbornik materialov dlja istorii imperatorskoj S.-Peterburgskoj Akademii Hudožestv za sto let ee suščestvovaniia [Recueil de documents sur l'histoire de l'Académie impériale des beauxarts de Saint-Pétersbourg en cent ans d'existence], SPb., 1864, p. 187-196.

47. Ce fut, par ailleurs, la comtesse Albani qui présenta à Šuvalov l'architecte Giacomo Trombara, Les consolations de l'absence, 1. 182.

48. Ibid., 1. 36-39.

49. Sur l'achat de la bibliothèque de Galiani, voir: Dimitri Ozerkov, « La bibliothèque architecturale de Catherine II ", in Olga Medvedkova, éd., Bibliothèques d'architecture/ Architectural libraries, P. : IN HA-Alain Baudry éditeur, 2009, p. 183-210.

50. Vladimir Levinson-Lessing, Istorija kartinnoj galerei Ermitaža (1764-1917) [Histoire de la galerie de peinture de l'Ermitage], L. : Iskusstvo, 1985, p. 271, note 102. Voir les planches de Raccolta d'antiche statue, busti, bassirilievi ed altre sculture de Bartolomeo Cavaceppi, t. 1-3, Rome, 1768-1772, marquées comme étant à Saint-Pétersbourg (" ora in Pietroburgo » ou «sta a Pietroburgo » ou " esiste in Pietroburgo »). Voir également Oleg Neverov, Grandes collections de la Russie impériale, P. : Flammarion, 2004, p. 57, ill. 65.

51. Petrov, Materialy; Levinson-Lessing, Istorija kartinnoj galerei Ermitaža, p. 271.

52. Levinson-Lessing, Istorija kartinnoj galerei Ermitaža, p. 95.

53. Petrov, Materialy, p. 198-202 : cette liste d'objets, excellente source pour l'histoire du goût - mentionnant matériaux et prix - est digne d'une traduction et d'une publication à part.

54. Oleg Neverov, «D.-B. Piranezi-sobiratel' antičnoj skul'ptury [Piranèse, collectionneur de la sculpture antique], in Muzej. Hudožestvennye sobranija SSSR, $n^{\circ} 4$, M., 1983, p. 234-244.

55. T. II, pl. 72 ou 75, selon les différents exemplaires du recueil. 
56. Levinson-Lessing, Istorija kartinnoj galerei Ermitaža, p. 96, qui cite d'après: SRIO (Sbornik Russkogo Istoričeskogo Obščestva), t. 33, 1881, p. 53.

57. L'affaire du marquis Maruzzi, RGADA, d. XVII, ed. hr. 276. Voir également: LevinsonLessing, Istorija kartinnoj galerei Ermitaža, p. 268-269.

58. En témoigne notamment sa correspondance avec F.M. Grimm : SRIO, t. 23, 44.

59. Les Consolations de l'absence, $1.84 \mathrm{v}-85$.

60. RGADA, f. 17, e. hr. 278.

61. RGADA, f. 17, e. hr. 279, 1. 3-5.

62. Ibid., 1. 3v.

63. Andrea Busiri Vici, «L'erudito della corte Russa del settecento, Ivan Ivanovitch Schouvaloff, ed i suoi rapporti con Roma », p. 39-52, note 23, p. 50.

64. Accademia di San Luca, Archivio.

65. Cette correspondance conservée dans le fonds 789 du RGIA est publiée partiellement dans Petrov, Materialy, p. 187-192.

66. Le premier projet d'une collection de sculptures antiques et de plâtres, qui devait servir aussi bien à la décoration des jardins royaux qu'aux besoins des jeunes artistes russes, fut élaboré par l'architecte Michetti aux début des années 1720. Voir: S.O. Androsov, «Dlja učenija rossijskih ljudej. O dejatel'nosti arhitektora Miketti po priobreteniju proizvedenij iskusstva v Italii [Pour l'apprentissage des Russes. L'achat des œuvres d'art par l'architecte Michetti] », Panorama iskusstv, n 10, 1987, p. 40-52.

67. Publié dans N.M. Moleva, E.M. Beljutin, Pedagogičeskaja sistema Akademii hudožestv v XVIII veke [Le système pédagogique de l'Académie des beaux-arts au xviii ${ }^{\mathrm{e}}$ siècle], M. : Iskusstvo, 1956, p. 388, note 12.

68. R.V. Golovenkova, «I.I. Šuvalov i pensionerstvo v imperatorskoj akademii hudožestv [Ivan Šuvalov et les pensionnaires de l'Académie impériale des beaux-arts], in Filosofskij vek, p. 43-47.

69. En 1770, l'Académie écrivait à Diderot : « Tous [les pensionnaires] ne manqueront pas le voyage à Paris, aussi bien que tous ceux qui commencent par la France n'échapperont pas au voyage d'Italie », RGIA, f. 789, op. 1, 1770, d. 12, 1. 58. Cité in: N. Kovalenskaja, Russkij klassicism. Živopis', skul'ptura, grafika [Le classicisme russe], M.: Iskusstvo, 1964, p. 396.

70. Petrov, Materialy, p. 188. Cette demande fut satisfaite et les pensionnaires russes reçurent la possibilité de prolonger leur séjour à Rome.

71. Petrov, Materialy, p. 189-190.

72. La correspondance de Reiffenstein avec l'Académie des beaux-arts, RGIA, f. 789, op. 1, č. I, 1771, d. 436, 1. 1-51v; 1. 1-1v. Cette correspondance attend sa publication complète par Christoph Frank.

73. Ibid., 1.1v.

74. Ibid., 1.2.

75. Ibid., 1.2v.

76. Ibid., 1. 4.

77. Ibid., 1. 4. 
78. Ibid., 1. 5. Cette lettre de Reiffenstein datait du 12 septembre 1770 : « Encouragé par les bontés de Son Excellence, Monsieur le General Schouvalow, qui a bien voulu donner part à l'Illustre Académie Impériale, de mon amour pour les beaux arts, et de quelque intelligence que j'en puisse avoir requise pendant un séjour de dix ans en Italie, j'ose presenter à Son Excellence le Chef Président et à tout l'illustre corps de l'Académie Impériale, le plus vif désir que je me sens d'acquerir quelque droit, de pouvoir pendent mon sejour à Rome que je désire de prolonger autant que je pourrois, me rendre utile à l'Académie Impériale des beaux-arts, comme en particulier à ceux qui la composent ou en dépendent. Ne pouvant y être autorisé plus convenablement, qu'en recevant l'honneur d'être agréé à ses membres honoraires, j'ose demander cette grâce et en même temps la permission de presenter des productions dans quelques branches des beaux arts, pour rendre au moins compte de l'amour avec lequel je les cultive, n'étant pas donné à un amateur de pouvoir le faire avec tant de succès. Ma très humble reconnaissance pour cette faveur sera d'autant plus vive si elle sera suivi des ordres de Son Excellence, en quoi je doivent témoigner ce respectueux attachement que je voue à jamais aux avantages de cet Illustre Institut et aux progrès des arts qui est le but de son Auguste fondation.» Ibid., 1. 6-7.

79. Ibid., 1. 8.

80. Ibid., 1. $48 \mathrm{v}-49$.

81. Conservés dans les archives de l'Académie des Beaux-Arts de Saint-Pétersbourg (actuellement : RGIA, f. 789), ces rapports ont été étudiés et en grande partie publiés, notamment dans: A. Trubnikov, « Pervye pensionery Imperatorskoj Akademii hudožestv [Les premiers pensionnaires de l'Académie impériale des beaux-arts] », Starye gody, avriljuin 1916, p. 67-92. Voir également : Trubnikov, « Pensionery Akademii hudožestv v XVIII veke [Les pensionnaires de l'Académie des beaux-arts au xviiie siècle]», Starye gody, juillet-septembre1907, p. 348-356; Denis Roche, "Slučaj iz žizni v Pariže pensionera Akademii hudožestv Kipriana Mel'nikova [Un épisode de la vie parisienne du pensionnaire Kiprian Mel'nikov), Starye gody, mai1908, p. 309-311; Roche "Perečen' russkih i pol'skih hudožnikov, imena kotoryh značatsja v spiskah parižskoj akademii živopisi i skul'ptury [Liste des peintres russes et polonais dont les noms se trouvent dans les procès-verbaux de l'académie de peinture et de sculpture de Paris], Starye gody, juin 1909, p. 306-315; V.K., « K istorii prebyvanija russkih hudožnikov za granicej [De l'histoire du séjour des peintres russes à l'étranger] », Starye gody, juin 1909, p. 338-339; Trubnikov, "Pervye pensionery Imperatorskoj Akademii hudožestv [Les premiers pensionnaires de l'Académie impériale des beaux-arts], Starye gody, avril-juin 1916, p. 67-92 ; Louis Réau "Les artistes russes à Paris au XVIII siècle ", Revue des Études slaves, III (3-4), 1923, p. 286-298.

82. Petrov, Materialy, p. 191, lettre de Saltykov à Šuvalov, du 13 août 1770.

83. La légende qui accompagne l'image de ce vase est la suivante: "Vase antique de marbre de grande taille représentant le Sacrifice d'Iphigénie offerte à l'idole de Diane pour apaiser ainsi la divinité, afin que les Grecs puissent se rendre avec sureté au siège de Troie ; mais par la pitié de la Déesse, une biche remplaça la jeune Iphigénie. Ce vase se voit dans la galerie des statues de la villa Médicis. À son Excellence le général Šuvalov lieutenant général des armées de sa majesté impériale de toutes les Russies, son Chambellan présent, chef du noble corps des Cadets, instigateur de l'académie des beauxarts, curateur de l'université de Moscou et chevalier des ordres de l'aigle blanc, de saint Aleksandr Nevskij et de sainte Anne, connaisseur savant et avisé des antiquités romaines 
et des beaux-arts ». Dans l'exemplaire de la bibliothèque de la RIBA, l'emplacement des ces deux gravures est inversé : celle qui montre le vase Borguèse clôt le second volume et celle avec le vase Médicis le premier, mais leur double position finale reste la même.

84. Voir, par exemple : Heather Hyde Minor, « Engraved in Porphyry, printed on paper : Piranesi and lord Charlemont ", The Serpent and the Stylus. Essayes on G.B. Piranesi, in Mario Bevilacqua, Heather Hyde Minor, Fabio Barry, éds., Michigan: Ann Arbor, 2006, p. 123-147.

85. La copie de ce vase, comme celles des nombreux autres vases figurants dans le recueil piranesien, se trouve dans le jardin de Pavlovsk.

86. Prince de Ligne, Mémoires, lettres et pensées, P. : Éditions François Bourin, 1989, p. 505.

87. De rerum natura, I, 80-100.

88. Sur le projet grec de Catherine II, voir notamment : Andrej Zorin, Kormja dvuhglavogo orla... Literatura i gosudarstvennaja ideologija $v$ Rossii $v$ poslednej treti XVII-pervoj treti XIX veka [Nourrir l'aigle bicéphale... Littérature et idéologie d'État en Russie au cours du dernier tiers du XVIII ${ }^{e}$ siècle et du premier tiers du XIX ${ }^{e}$ siècle], M. : Novoe Literaturnoe Obozrenie, 2001.

89. RNB, Saint-Pétersbourg, département des manuscrits, f. 875, Šuvalov, $N^{\circ} 3,1.14$.

90. 1772, huile sur toile, Galerie Tret'jakov.

91. RNB, Saint-Pétersbourg, département des manuscrits f. 875, Šuvalov, $N^{\circ} 3,1.18-18 \mathrm{v}$.

92. Voir: Emilie Beck-Saiello, Pierre Jacques Volaire, dit le Chevalier Volaire, P.: Arthena, 2010.

93. RGIA, f. 468, op. 1, č. II, 1772, d. 3887, 1. 35-36. Cité dans : N.N. Nikulin, Jacob Philipp Hackert, catalogue de l'exposition, Ermitage, SPb., 1998, p. 7, 14, note 7.

94. GalerieTret'jakov, début des années 1780.

95. Brenna qui, par ailleurs, signe l'une des planches des Vasi.

\section{AUTEUR}

\section{OLGA MEDVEDKOVA}

CNRS, Centre André Chastel 